\title{
Online Course Evaluations Response Rates
}

Faruk Guder, Loyola University Chicago, USA

Mary Malliaris, Loyola University Chicago, USA

\begin{abstract}
This paper studies the reasons for low response rates in online evaluations. Survey data are collected from the students to understand factors that might affect student participation in the course evaluation process. When course evaluations were opened to the student body, an email announcement was sent to all students, and a reminder email was sent a week later. Our study showed that participation rates increased not only when emails were sent, but also when faculty used in-class time to emphasize the importance of completing the evaluations.
\end{abstract}

Keywords: Course Evaluations; Online Evaluation; Participation Rate

\section{INTRODUCTION}

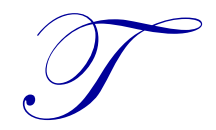

eacher and course evaluations are conducted at the end of each academic term. We often assume that students look forward to the opportunity to give their opinions about the classes they have just completed. In today's environment, we also believe that students are comfortable with expressing their opinions online. Taking these two assumptions together, we might expect that students would always take advantage of the opportunity to express their opinions about their classes in an online setting. However, most research indicates that student response rates collected online are far lower than those collected on paper. In fact, Nulty (2008) reports overall results from a number of online evaluation cases and finds that the online response rate averaged out to a drop of $23 \%$ in comparison to the in-class collection response rate. In spite of this drop in response rates, institutions continue to switch to the online format for collection of course evaluation data. Anderson et al (2006) reported that the number of institutions using online evaluations rose from $2 \%$ in 2000 to $33 \%$ in 2005 .

The Quinlan School of Business at Loyola University Chicago moved from in-class to online evaluations for the entire set of classes that we offer at both the undergraduate and graduate levels in the spring term of 2009. Across all departments, there was a significant drop in the number of responses. However, analysis of the results showed that there was no significant difference in the paper and online values given to courses or faculty for whom evaluations existed in both paper and online formats (Guder et al, 2009). However, with the online evaluations, the response rate dropped by $26 \%$ on the undergraduate level (Guder \& Malliaris, 2010). Given this significant drop, we were interested in not only the comparison of values with the previous years, but also why the drop might have occurred.

Anderson, Brown and Spaeth (2006) briefly explored, with a small number of students, why students did not respond to an online evaluation and grouped the responses into the following four reasons: 1) the students were disengaged (that is, they forgot or were too busy), 2) they had technology problems, 3) they perceived no benefit from participation, or 4) "other". Expanding upon this study, we surveyed a large number of students representative of both the graduate and undergraduate populations to investigate the reasons behind their level of participation in the course evaluation process.

\section{DATA}

A brief questionnaire with items about participation in the previous term's online course evaluation system was distributed to both undergraduate and graduate students during class. For most questions, the students were asked to circle the appropriate answer. However, we also gave the students space to give two open-ended responses at the end. Each of the students was asked to respond to three questions about basic interaction with the survey: 1) 
did you receive the initial email, 2) did you receive the reminder email, and 3) did your instructor encourage you to complete the evaluation. The course evaluation system pulls the list of student names from the official class registration system and all students who are officially enrolled receive the email. However, not all students regularly check their school email. That is, they can say they did not receive an email when they actually mean they did not check their university email account for the notice. Within the system that is used at Loyola, if a student has filled out the evaluations as a result of the initial email, no reminder is sent to them. Reminder emails go only to the students who have not completed all of their set of evaluations.

Following these three initial questions, they then identified if they completed All, Some, or None of their evaluations. If they responded with Some or None, then they were given a set of reasons to select from for their non-response (forgot to do them, was too busy, worried about being identified, evaluations don't matter, other_ ). Finally, students were asked for their opinion of how we could encourage greater response in the future.

To help in understanding factors that might affect student participation in the course evaluation process, we collected data from a representative and non-overlapping group. That is, we gathered data from all classes taught at the same time on the same day. In the undergraduate school, all students attending classes taught on Tuesday and Thursdays from 11:30 to 12:45 were given surveys in class and asked to complete them if they had taken classes in the SBA during the previous term. On the graduate level, all classes taught on Mondays (6:00-9:00 pm) were asked to participate. Using this method, we were able to obtain input from students in both the core and advanced classes. Each student surveyed was unique ensuring no duplication or redundancy. The selection of students who took the survey represented $42 \%$ of all enrolled graduate students and $36 \%$ of all enrolled undergraduates. At least one class from each of the academic areas was included in the survey. Responses referred to only the immediately previous term. The number of students at each level who completed the survey are shown in Table 1.

Table 1: Number of Students Completing the Survey

\begin{tabular}{|l|c|}
\hline \multicolumn{1}{|c|}{ Level } & Total \\
\hline Graduate & 341 \\
\hline Undergraduate & 771 \\
\hline Grand Total & 1112 \\
\hline
\end{tabular}

\section{RESULTS}

Students were asked whether they had completed All, Some, or None of the previous term's course evaluations. The percentage of graduate and undergraduate students in each of those categories is given in Table 2. The results are shown as percent of level.

Table 2: Percentage Completing All, Some, or None of Their Evaluations

\begin{tabular}{|l|c|c|c|c|}
\hline \multicolumn{1}{|c|}{ Level } & All & Some & None & Total \\
\hline Graduate & $67.45 \%$ & $13.49 \%$ & $19.06 \%$ & $100.00 \%$ \\
\hline Undergraduate & $44.10 \%$ & $41.50 \%$ & $14.40 \%$ & $100.00 \%$ \\
\hline
\end{tabular}

Graduate students were more likely than undergraduates to complete all their evaluations. Typical graduate students, most who work full-time, however, take two or three courses per term, while the undergraduates typically take five or six. We further see that if a graduate student does not complete all the evaluations, they are more likely to do none of them rather than to do a partial set. On the undergraduate side, if a student does not do all of the evaluations, they are more likely to do some of them than none. A topic for further study might be the selection of courses they choose to evaluate if they are not doing all of them. It is also of interest to note that the percentage of undergraduates completing none of their evaluations is smaller than the graduate percentage.

Within the categories of All, Some, and None, we then looked at the percentage of students who recalled faculty mention of the evaluation process. Was there any effect from having the teacher specifically encourage the students to complete the course evaluations? When a teacher mentions, in class, the importance of filling out the evaluations, it brings the evaluations to the student's attention and increases the likelihood that they might look at the email rather than deleting without opening it. Table 3 shows that, on both the graduate and undergraduate levels, 
the students who filled out all of the evaluations were more likely to have been encouraged by some faculty member to do so.

\begin{tabular}{|c|c|c|c|c|c|}
\hline Level & Encouraged & All & Some & None & Total \\
\hline \multirow[t]{2}{*}{ Graduate } & $\mathrm{No}$ & $60.94 \%$ & $15.63 \%$ & $23.44 \%$ & $100.00 \%$ \\
\hline & Yes & $68.95 \%$ & $13.00 \%$ & $18.05 \%$ & $100.00 \%$ \\
\hline \multirow[t]{2}{*}{ Undergraduate } & No & $31.69 \%$ & $50.00 \%$ & $18.31 \%$ & $100.00 \%$ \\
\hline & Yes & $46.90 \%$ & $39.59 \%$ & $13.51 \%$ & $100.00 \%$ \\
\hline
\end{tabular}

Specifically on the graduate level, for the set of students in classes where no teacher encouraged them to fill out the evaluations, about $61 \%$ of them completed all the evaluations anyway, while about $23 \%$ completed none of them. For the graduate students who had some teacher mention the importance of responding to the email, $69 \%$ completed all their course evaluations, while $18 \%$ did none of them. For those who completed some of the evaluations, the in-class mention by the professor was not beneficial. On the undergraduate side, if no professor encouraged them to complete their course evaluations, only around $32 \%$ of them filled all of them out, while $50 \%$ completed some and $18 \%$ did none. For undergraduates who had a faculty mention the importance of this process, $47 \%$ filled out all their evaluations, almost $40 \%$ did some of them and less than $14 \%$ did none of them. Almost $47 \%$ of the undergraduates who were encouraged completed all their evaluations, which, compared with $32 \%$ of those who were not encouraged, is an increase of $15 \%$.

In both the graduate and undergraduate cases, the percent of students who completely disregarded the process by filling out none of their evaluations was smaller for those who had received encouragement by a faculty member than for those where no faculty member brought up the importance of the evaluations in class.

Table 4 adds the information from the two questions of whether they remembered receiving the original email and the reminder. Recall that the reminder was sent only to those who had not already completed their course evaluations. For the graduate students, notice that they all recalled receiving the original email with the link to the evaluation form. The largest percentages of those who filled out all their evaluations go to those who were encouraged by some teacher to do so. The largest percentages of the graduate students who completed none of their evaluations goes to those who received no encouragement from faculty regardless of emails and reminders.

Table 4: Responses by Level for Encouragement, Email, and Reminder

\begin{tabular}{|c|c|c|c|c|c|c|c|}
\hline Level & Encouraged & Email & Reminder & All & Some & None & Total \\
\hline Graduate & No & Yes & No & $50.00 \%$ & $25.00 \%$ & $25.00 \%$ & $100 \%$ \\
\hline & No & Yes & Yes & $61.67 \%$ & $15.00 \%$ & $23.33 \%$ & $100 \%$ \\
\hline & Yes & Yes & No & $72.22 \%$ & $16.67 \%$ & $11.11 \%$ & $100 \%$ \\
\hline & Yes & Yes & Yes & $68.73 \%$ & $12.74 \%$ & $18.53 \%$ & $100 \%$ \\
\hline Undergraduate & No & Yes & No & $40.00 \%$ & $46.67 \%$ & $13.33 \%$ & $100 \%$ \\
\hline & No & Yes & Yes & $30.71 \%$ & $50.39 \%$ & $18.90 \%$ & $100 \%$ \\
\hline & Yes & No & Yes & $16.67 \%$ & $66.67 \%$ & $16.67 \%$ & $100 \%$ \\
\hline & Yes & Yes & No & $51.61 \%$ & $45.16 \%$ & $3.23 \%$ & $100 \%$ \\
\hline & Yes & Yes & Yes & $46.96 \%$ & $39.02 \%$ & $14.02 \%$ & $100 \%$ \\
\hline
\end{tabular}

In the undergraduate portion of the table, we see that the percentages of students who filled out some of their evaluations were much greater than on the graduate side. As one undergraduate stated, "I only did it if teachers were really good or really bad. [I was] too lazy to do surveys for mediocre teachers." A student might have missed the class in which the professor mentioned the evaluation or he does not regularly check emails. However, when their peers in the dorms mention that they filled out their questionnaires, a student could find the site, log in, and fill theirs out. The group that did not recall receiving the initial email, but was encouraged by faculty to respond, did complete some of their evaluations when they received the reminder. So, for the undergraduates, all three reinforcements played a part in their response levels.

In comparison to the graduate students, undergraduates were interested in responding but did not feel the same level of concern or involvement about all the classes they took. Thus, the percentage completing all their evaluations is lower for most of the rows than among corresponding graduate groups. 
Students responding to only some or none of their evaluations were asked to select the reasons that corresponded best to why they had not completed all their evaluations. Students were instructed to circle all the reasons that applied to them, so many selected more than one reason. The results are displayed in Table 5 and divided into those who filled out some of the evaluations and those who did none. We see that on both the graduate and undergraduate levels, a very small percentage of students are worried about being identified by the system. The emails that they receive clearly state that there will be no identifying data attached to their responses. Anderson et al (2006) refer to students who respond as "busy" or "they forgot" as being "disengaged" with the process of evaluation. Among the graduate students, these reasons were selected by the largest number of students who completed none of the evaluations. Within the undergraduate group, those who completed only some of the evaluations also selected 'busy' and 'forgot' most, but they were also more likely to select 'busy' than 'forgot'. A much greater percentage of undergraduates felt that evaluations simply don't matter, thus, it was a conscious decision on their part to not participate.

Table 5: Reasons for Non-Response (Multiple Answers Allowed)

\begin{tabular}{|l|c|c|c|c|c|c|}
\hline \multicolumn{1}{|c|}{ Level } & & Don't Matter & Forgot & Busy & Identify Me & Other \\
\hline Graduate & None & $7.69 \%$ & $49.23 \%$ & $50.77 \%$ & $6.15 \%$ & $16.92 \%$ \\
\hline Graduate & Some & $4.35 \%$ & $41.30 \%$ & $39.13 \%$ & $6.52 \%$ & $23.91 \%$ \\
\hline Graduate Total & & $6.31 \%$ & $45.95 \%$ & $45.95 \%$ & $6.31 \%$ & $19.82 \%$ \\
\hline & & & & & & \\
\hline Undergraduate & None & $17.12 \%$ & $38.74 \%$ & $63.06 \%$ & $3.60 \%$ & $17.12 \%$ \\
\hline Undergraduate & Some & $14.38 \%$ & $48.75 \%$ & $65.63 \%$ & $6.25 \%$ & $11.88 \%$ \\
\hline Undergraduate Total & & $15.08 \%$ & $46.17 \%$ & $64.97 \%$ & $5.57 \%$ & $13.23 \%$ \\
\hline
\end{tabular}

Among the answers under the choice "other", many of the written comments indicated that students completed evaluations when they felt that the class was either very good or very bad. Otherwise, they did not respond. Examples of this type of response were: "Nothing positive or negative to say about the class", "If the class is average, there is nothing to complain about and there is nothing exceptional, then evaluation is just a waste of time", "I only fill out for the profs I really enjoy or really don't enjoy", and "I had no strong opinions either way about some courses". Another category of written answers indicated that students were not aware of any impact their evaluations could have for them or the class. For example, "Most professors don't read or change according to what we write", "Evaluations don't change any teacher's teaching style", and "Class is done, I can't take it again, so I don't bother evaluating the class". The third type of other comment that occurred most often concerned the evaluation instrument itself. Examples include, "They take too long", "Surveys were long", "The electronic ones take longer to complete", and "Way too long!!"

\section{CONCLUSIONS}

The responses of over a thousand of our students to this brief survey have given us insight into the process of online evaluations. The subsequent analyses we performed offered several suggestions about how we might increase student engagement in this procedure. To begin with, our studies showed that faculty encouragement had a positive effect on both the undergraduate and graduate level in increasing student participation. Furthermore, the original email and the reminder email were both noted to be necessary parts of increasing student awareness and response. Future efforts, as such, will prompt faculty to promote the importance of completing online evaluations (during class time) and the initial email and reminders will continue to be implemented in the evaluation process. Finally, based on student comments, future studies in this area will consider ways the questionnaire can be revised so that its length (currently 20 multiple choice questions followed by 3 open-ended responses) is not a deterrent in student completion of the evaluations.

\section{AUTHOR INFORMATION}

Faruk Guder is Associate Dean and professor of Operations Management in the Quinlan School of Business at Loyola University Chicago. He teaches courses in the areas of operations management, quality management, and statistics. His research interests are in the areas of quality management, inventory management, and distribution facilities location in a price-responsive environment. E-mail: fguder@luc.edu (corresponding author). 
Mary Malliaris is the department chairperson and Professor of Information Systems \& Operations Management in the Quinlan School of Business at Loyola University Chicago. She teaches courses in the area of data analysis including data mining, informatics, financial modeling, and statistics. She has research interests in several areas including applications of neural networks, modeling financial markets, hospital professional practice environments and gender in IT. E-mail: mmallia@luc.edu

\section{REFERENCES}

1. Duncan, N. (2008). The Adequecy of Response Rates to Online and Paper Surveys: What can be done? Assessment \& Evaluation in Higher Education, 33(3), 301-314.

2. Anderson, J., G. Brown, and S. Spaeth, (2006). Online Student Evaluations and Response Rates Reconsidered. Innovate 2 (6).

3. Boysen, G. (Jul 2008). Revenge and Student Evaluations of Teaching, Teaching of Psychology, 35(3), 218222.

4. Brown, M., Baillie, M., and Fraser, S. (Spr 2009). Rating Ratemyprofessors.com: A Comparison of Online and Official Student Evaluations of Teaching, College Teaching, 57(2), 89-92.

5. Clayson, D. (2009). Student Evaluations of Teaching: Are They Related to What Students Learn? -A Meta-Analysis and Review of the Literature, Journal of Marketing Education, 31(1), 16-30.

6. Guder, F., Malliaris, M., and Jalilvand, A. (2009). Changing the Culture of a School: The Effect of Larger Class Size on Instructor and Student Performance, American Journal of Business Education, 2 (9), 83-89.

7. Guder, F., and Malliaris, M. (2010). Online and Paper Evaluations, American Journal of Business Education, 3 (2) 131-137. 
NOTES 